\title{
Erdheim-Chester Disease with Revealing Mandibular Localization: About A Case
}

\author{
El Masloumi.A*, Hajjine A, Chehboun A, Boutakioute B, Ouali Idrissi M, Cherif Idrissi El Ganouni N
}

Departement of Radiology, Mother and Child's Hospital, Mohammed VIth Teaching Center, Medical school of Marrakesh, CadiAyad University, Marrakesh, Morocco

DOI: $10.36347 /$ simcr.2020.v08i03.026

| Received: 09.03.2020 | Accepted: 16.03.2020 | Published: 18.03.2020

*Corresponding author: El Masloumi.A

Abstract

Case Report

Erdheim-Chester disease is a rare systemic Langrehansian histiocytosis. It is diagnosed on the basis of a bundle of clinical, radiological and histological arguments. Its confirmation is based on a precise immunological profile. The bone involvement is almost constant, characterized by osteocondensing lesions more often at the metaphyssodiaphyseal level of the long bones of the lower limbs. We report the case of a 37-year-old female patient with chronic left jugular swelling. The CT scan revealed a mandibular osteolytic lesion including the cortex without extension towards the soft parts. The diagnosis of EDC was established based on the histological aspect of the lesion and confirmed by the immunohistochemical study.

Key words: Erdheim-Chester Disease, Histiocytosis, Mandible, Osteolysis.

Copyright @ 2020: This is an open-access article distributed under the terms of the Creative Commons Attribution license which permits unrestricted use, distribution, and reproduction in any medium for non-commercial use (NonCommercial, or CC-BY-NC) provided the original author and source are credited.

\section{INTRODUCTION}

Erdheim-Chester disease is a rare multisystemic non-Langerhansian histiocytosis, characterized by almost constant bone involvement and a rich and diverse symptomatology making its diagnosis difficult which is essentially based on histopathological analysis and a specific immunohistochemical profile [1]. The bone involvement can be suggestive in its classic form, which is manifested by bilateral and symmetrical osteocondensation of the metaphysso-diaphyseal cancellous bone of the long bones, with predominance in the lower limbs. Nevertheless it can be atypical with lytic lesions taking on a tumor aspect [2]. The mandibular localization is exceptional and rarely described in the literature, which prompted the publication of this clinical-radiological case.

\section{Case Report}

We report the case of a 37-year-old woman with a history of chronic bilateral knee and ankle arthralgia and two episodes of self-resolving redness of the eye who consults for a left jugular swelling progressively developing over 6 months.

Clinically, we assess a solid left jugular mass, fixed relative to the deep plane without signs of local inflammation, associated with a bilateral erythematous conjunctivitis. The rest of the clinical examination was of no particularities.

Blood tests requested initially were normal with a leukocyte count at $8500 \mathrm{U} / \mathrm{ml}$, an erythrocyte sedimentation rate at $6 \mathrm{~mm} / \mathrm{h}$ and a CRP at $1.2 \mathrm{mg} /$ dL.

A craniofacial CT scan was carried out and objectified an osteolytic lesion of the left hemimandible affecting the ramus and the horizontal branch with blowing and rupture of the cortex in places (Fig 1 3 ) with noextension to the soft parts surrounding it and deep spaces of the face (fig 2).

Subsequently, a phosphocalcic blood test was requested showing a low level of serum vitamin D (15 $\mathrm{ng} / \mathrm{ml}$ ) with normal values for: alkaline phosphatases (79 U / L), LDH (207 U / L), CK (51 IU / L), Calcemia (95 mg / L) and Phosphoremia (26 mg / L). The tumor markers CA15-3, CA125 and CA 19-9 were negative.

Surgical biopsy of the mandibular lesion with anatomopathological study, showed layers of foaming histiocytes with enlarged nuclei associated with some inflammatory elements such as lymphocytes, plasma cells and neutrophils without specific granuloma with mature bone tissue at the periphery of the lesion composed of thick osseous spans sheltering Haversian 
canals, as well as large hematic layers and heaps of focal atypical histiocytes without mitosis. The complement by immuno-histochemistry was in favor of a non-langerhansian histiocytosis with an anti-CD68 positive, anti-CD1a and anti-protein S-100 negative.

The diagnosis of Erdheim-Chester disease was therefore retained based on the clinical manifestations and histological and immunological confirmation.
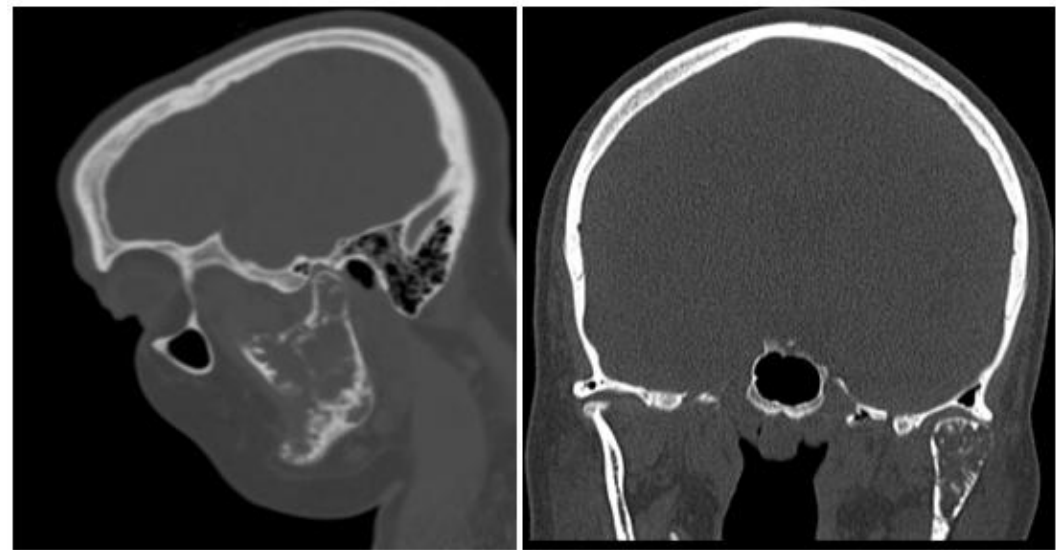

Fig-1: Facial CT, bone window, sagittal (1A) and coronal (1B) section: osteolytic lesion of the left hemi-mandible involving the ramus and the horizontal branch with blowing and rupture of the cortex in certain aeras

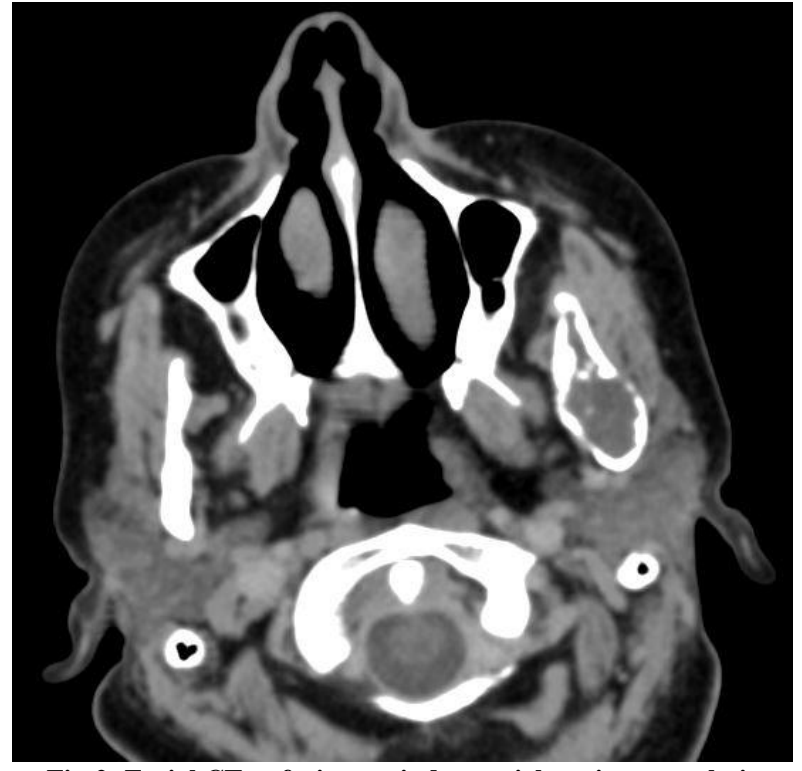

Fig-2: Facial CT, soft tissue window, axial section: osteolytic lesion of the left hemi-mandible with blowing and rupture of the cortex in places respecting the adjacent soft parts and deep spaces of the face

\section{DiSCUSSION}

Erdheim-Chester disease was first described in 1930 by Viennese pathologist Jakob Erdheim, a pupil of William Chester [1, 3, 4]. It is a non-Langerhansian histiocytosis characterized by specific immunostaining and by the absence of the Birbeck granule found in Langerhansian histiocytosis [5].
In addition, the mandibular location as well as the radiological aspect of the bone involvement are not characteristic of this disease, but can be found in its atypical form.

As part of the assessment of this disease, $\mathrm{x}$ rays of the two lower limbs were requested as well as a bone scan, an abdomino-pelvic ultrasound and a thoraco-abdomino-pelvic CT scan and which did not reveal any other location or visceral involvement. 
of aspecific, moderate bone pain with no particular rhythm prevailing in the lower limbs, painless bilateral exophthalmos and by diabetes insipidus which can precede the other symptoms of a few years. Therefore, the disease is suspected before a bundle of clinical and radiological arguments, and can only be confirmed by an anatomopathological, immunohistochemical and molecular study.

Histologically, it is characterized by the presence of foamy histiocytes with a high lipid content or of giant polynucleated cells loaded with lipids (Touton cells) and which can be associated with fibrosis plaques, gigantocellular granulomas or a Polynuclear and lymphocytic inflammatory infiltrate. These histiocytes express CD68 and CD163 but not CD1a with variable expression of the protein $\mathrm{S} 100$ and factor XIIIa, which makes it possible - in addition to the absence of the Bribeck granule - to differentiate nonLangerhansian histiocytosis from Erdheim -Chester of Langerhansian histiocytosis [10, 11]. Molecular analysis can reveal the BRAFV600E mutation [12].

Classic bone involvement is characterized on xray and on computed tomography by bilateral and symmetrical metaphyso-diaphyseal bone marrow osteocondensation of the long bones (distal ends of the femurs and proximal of the tibias) with respect for the epiphyses, sub chondral regions, parts soft and extremities. An endosteal cortical reaction is noted giving a dimmed appearance of the cortico-medullary junction. It is sometimes associated with a periosteal reaction in $1 / 3$ of the cases or foci of osteonecrosis by peri-adventitious histiocytic infiltration (microangiopathy) $[2,13-15$.

In atypical forms, the bone involvement can be a type of pseudo-tumor focal osteolytic lesions with soft tissue damage, or mixed combining osteosclerosis and bone lysis [16-20].

In our patient, osteolytic involvement of the ramus and the horizontal branch of the left hemimandible was the only bone lesion found and indicative of the disease. This localization and its osteolytic nature remain exceptional in Erdheim Chester disease unlike Langerhansian histiocytosis where it is usually found.

MRI confirms the medullary infiltration which appears in hyposignal T1, hypersignal $\mathrm{T} 2$, with heterogeneous enhancement involving the diaphysometaphyseal and partially epiphyseal regions, sparing the subchondral regions and thus making it possible to determine the clear boundaries between healthy zones and pathological areas. It can be associated with a periostitis which is manifested by a T2 hypersignal or by a linear peri-cortical enhancement [21, 22].

Bone scintigraphy, SPECT-CT with $18 \mathrm{mTc}$ diphosphonates or PET-scanner with 18FDG are sensitive to the early phase of the disease showing bilateral and symmetrical diaphyseal and metaphysoepiphyseal hyperfixation [23].

Bilateral and symmetrical peri-renal involvement represents the most frequent extra-osseous location, giving a so-called hairy kidney appearance on CT with sheathing of the renal sinuses and lumbar ureters or mega-calicosis. The radiological distinction with idiopathic retro peritoneal fibrosis (Ormond disease) or with a disease associated with IgG4 is sometimes difficult without a complete histology [24].

Pulmonary involvement may manifest as dyspnea, cough or even respiratory failure with interstitial chest CT syndrome caused by thickening of the interlobular septa, thickening of the scabs, micronodular centrolobular opacities or lymphangitic distribution sometimes associated with effusion plural. The study of the LBA fluid can reveal CD68 + CD1aspumous histiocytes [25].

Cardiovascular involvement is most often manifested by peri-aortic infiltration in the "aortic mantle" (coated aorta), circumferential, homogeneous, regular, rather peri-adventitious than parietal, which may extend

\section{REFERENCES}

1. Chester W. Über lipoidgranulomatose. Virchows Archiv für pathologische Anatomie und Physiologie und für klinische Medizin. $1930 \mathrm{Dec}$ 1;279(2):561-602.

2. Adib O, Baroth E, Perard L, Scoazec JY, Vervueren L, Aubé C, Willoteaux S. Imagerie des localisations osseuses et extra-osseuses de la maladie d'Erdheim-Chester. Journal de radiologie. 2011 Jul 1;92(7-8):671-80.

3. C Campochiaro A Tomelleri G Cavalli A Berti L. Dagna Erdheim-Chester disease. Eur J Intern Med 2015 (26) //

4. Romm S. Jakob Erdheim: Eminent Pathologist of Vienna. The American Journal of Dermatopathology. 1987 Oct 1;9(5):447-50.

5. Andre R, Seebach JD. La maladie d'Erdheim Chester: un diagnostic différentiel de fibrose rétropéritonéale. Revue médicale suisse. 2017;13(557):743-7.

6. Chasset F, Barete S, Charlotte F, Cohen-Aubart F, Arnaud L, Le Pelletier F, Emile JF, Francès C, Amoura Z, Haroche J. Cutaneous manifestations of Erdheim-Chester disease (ECD): clinical, pathological, and molecular features in a monocentric series of 40 patients. Journal of the American Academy of Dermatology. 2016 Mar 1;74(3):513-20.

7. Diamond EL, Dagna L, Hyman DM, Cavalli G, Janku F, Estrada-Veras J, Ferrarini M, AbdelWahab O, Heaney ML, Scheel PJ, Feeley NK. Consensus guidelines for the diagnosis and clinical 
management of Erdheim-Chester disease. Blood. 2014 Jul 24;124(4):483-92.

8. Park M, Boone B, Devos S. Xanthoma disseminatum: case report and mini-review of the literature. Acta Dermatovenerol Croat. 2014;22:150-154

9. Veyssier-Belot C, Cacoub P, Caparros-Lefebvre D. Erdheim-Chester disease: clinical and radiologic characteristics of 59 cases. Medicine (Baltimore). 1996;75:157-169.

10. Chisolm SS, Schulman JM, Fox LP. Adult xanthogranuloma, reticulohistiocytosis, and RosaiDorfman Disease. Dermatol Clin. 2015;33:465472. discussion 473

11. Caputo R, Marzano AV, Passoni E, Berti E. Unusual variants of non-Langerhans cell histiocytoses. J Am Acad Dermatol. 2007; 57:1031-1045.

12. JF Emile F Charlotte C ChassagneClement Histiocytoses: general classification and molecular criteria. Presse Med 2017 (46

13. Veyssier-Belot C, Cacoub P, Caparros-Lefebvre D, Wechsler J, Brun B, Remy M, Wallaert B, Petit H, Grimaldi A, Wechsler B, Godeau P. ErdheimChester disease. Clinical and radiologic characteristics of 59 cases. Medicine. 1996 May;75(3):157-69.

14. Pertuiset E, Laredo JD, Liote F, Wassef $M$, Jagueux M, Kuntz D. Erdheim-Chester disease: report of a case, review of the literature and discussion of the relation to Langerhans-cell histiocytosis. Revue du rhumatisme (Ed. francaise: 1993). 1993 Oct;60(9):601-9.

15. Murray D, Marshall M, England E, Mander J, Chakera TM. Erdheim-chester disease. Clinical radiology. 2001 Jun;56(6):481-4.

16. Gomez C, Diard F, Chateil JF, Moinard M, Dousset V, Rivel J. Imaging of Erdheim-Chester disease. Journal de radiologie. 1996 Dec;77(12):1213-21.

17. Kushihashi T, Munechika H, Sekimizu M, Fujimaki E. Erdheim-Chester disease involving bilateral lower extremities: MR features. American Journal of Roentgenology. 2000 Mar;174(3):875-6.

18. Ivan D, Neto A, Lemos L, Gupta A. ErdheimChester disease: a unique presentation with liver involvement and vertebral osteolytic lesions. Archives of pathology \& laboratory medicine. 2003 Aug;127(8):e337-9.

19. Lyders EM, Kaushik S, Perez-Berenguer J, Henry DA. Aggressive and atypical manifestations of Erdheim-Chester disease. Clinical rheumatology. 2003 Dec 1;22(6):464-6.
20. Kenn W, Stäbler A, Zachoval R, Zietz C, Raum W, Wittenberg G. Erdheim-Chester disease: a case report and literature overview. European radiology. 1999 Jan 1;9(1):153-8.

21. Yamamoto T, Mizuno K. Erdheim-Chester disease with intramuscular lipogranuloma. Skeletal radiology. 2000 Apr 1;29(4):227-30.

22. Waite RJ, Doherty PW, Liepman M, Woda B. Langerhans cell histiocytosis with the radiographic findings of Erdheim-Chester disease. AJR Am J Roentgenol. 1988;150:869-871.

23. Spyridonidis TJ, Giannakenas C, Barla P, Apostolopoulos DJ. Erdheim-Chester disease: a rare syndrome with a characteristic bone scintigraphy pattern. Annals of nuclear medicine. 2008 May 1;22(4):323-6.

24. Gianfreda D, Musetti C, Nicastro M, Maritati F, Cobelli R, Corradi D, Vaglio A. Erdheim-Chester disease as a mimic of IgG4-related disease: a case report and a review of a single-center cohort. Medicine. 2016 May;95(21).

25. Egan AM, Boardman LA, Tazelaar HD, Swensen SJ, Jett JR, Yousem SA, Myers JL. ErdheimChester disease: clinical, radiologic, and histopathologic findings in five patients with interstitial lung disease. The American journal of surgical pathology. 1999 Jan 1;23(1):17-26.

26. Nicolazzi MA, Carnicelli A, Fuorlo M, Favuzzi AM, Landolfi R. Cardiovascular involvement in Erdheim-Chester disease: a case report and review of the literature. Medicine. 2015 Oct;94(43).

27. Lachenal F, Cotton F, Desmurs-Clavel H, Haroche J, Taillia H, Magy N, Hamidou M, Salvatierra J, Piette JC, Vital-Durand D, Rousset H. Neurological manifestations and neuroradiological presentation of Erdheim-Chester disease: report of 6 cases and systematic review of the literature. Journal of neurology. 2006 Oct 1;253(10):1267-77.

28. Drier A, Haroche J, Savatovsky J, Godenèche G, Dormont D, Chiras J, Amoura Z, Bonneville F. Cerebral, facial, and orbital involvement in Erdheim-Chester disease: CT and MR imaging findings. Radiology. 2010 May;255(2):586-94.

29. Chasset F, Barete S, Charlotte F, Cohen-Aubart F, Arnaud L, Le Pelletier F, Emile JF, Francès C, Amoura Z, Haroche J. Cutaneous manifestations of Erdheim-Chester disease (ECD): clinical, pathological, and molecular features in a monocentric series of 40 patients. Journal of the American Academy of Dermatology. 2016 Mar 1;74(3):513-20. 